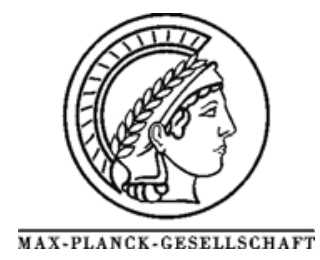

\title{
Methanol oxidation on a copper catalyst investigated using in situ X-ray photoelectron spectroscopy
}

\author{
H. Bluhm ${ }^{1+* *}$, M. Hävecker ${ }^{1}$, A. Knop-Gericke ${ }^{1}$, E. Kleimenov ${ }^{1}$, R. Schlögl ${ }^{1}$, D. Teschner ${ }^{2}$, \\ V.I. Bukhtiyarov ${ }^{3}$, D.F. Ogletree ${ }^{4}$, M. Salmeron ${ }^{4}$
}

\author{
${ }^{1}$ Department of Inorganic Chemistry, Fritz-Haber-Institute of the MPG, Faradayweg 4-6, 14195 Berlin, Germany \\ ${ }^{2}$ Institute of Isotope \& Surface Chemistry, CRC, Hungarian Academy of Sciences, P. O. Box 77, Budapest, H-1525 \\ Hungary \\ ${ }^{3}$ Boreskov Institute of Catalysis, 6300090 Novosibirsk, Russia \\ ${ }^{4}$ Lawrence Berkeley National Laboratory, Materials Sciences Division, One Cyclotron Road, Berkeley, \\ CA 94720, USA \\ \#present address: Lawrence Berkeley National Laboratory, Chemical Sciences Division, Mail Stop 4R0230, Berke- \\ ley, CA 94720, USA. \\ *Corresponding author: e-mail bluhm@ffhi-berlin.mpg.de, hbluhm@lbl.gov,
}

Received: January 28, 2004, in final form March 25, 2004

\begin{abstract}
The surface and near-surface region of an active catalyst and the adjacent gas-phase reactants were investigated simultaneously under reaction conditions using in situ X-ray photoelectron spectroscopy (XPS). This investigation of methanol oxidation on a copper catalyst showed that there was a linear correlation between the catalytic activity of the sample and the presence of a sub-surface oxygen species that can only be observed in situ. The concentration profile of the sub-surface oxygen species within the first few nanometers below the surface was determined using photon energy-dependent depth-profiling. The chemical composition of the surface and the near-surface region varied strongly with the oxygen-tomethanol ratio in the reactant stream. The experiments show that the pure metal is not an active catalyst for the methanol oxidation reaction, but that a certain amount of oxygen has to be present in the sub-surface region to activate the catalytic reaction. Oxide formation was found to be detrimental to formaldehyde production. Our results demonstrate also that for an understanding of heterogeneous catalysts a characterization of the surface alone may not be sufficient, and that sub-surface characterization is essential.
\end{abstract}

Keywords: X-ray photoelectron spectroscopy; catalysis; alcohols; oxidation; copper

\section{Introduction}

One of the foremost goals of catalytic research is to unravel the atomic level structure of the catalyst surface and the processes occurring during synthesis operation. Studies under high vacuum conditions have provided detailed information about the adsorption and stoichiometric reaction of molecules on well-defined surfaces.[1] However, the surface chemistry under those relatively static conditions might be very different from the dynamic surface chemistry at higher pressures.[2] In the past the in situ investigation of catalyst surfaces was difficult, because the most surface sensitive imaging and spectroscopy techniques were restricted to high vacuum conditions.[3,4] Recent instrumental developments however, have made possible the investigations at elevated pressures using imaging [5-10] and spectroscopic [11,12,13] methods, among them X-ray photoelectron spectroscopy (XPS) $[14,15,16]$ that has been shown to be able to operate at pressures of up to 10 mbar. [17,18] Here we present the use of XPS at millibar pressures to determine the chemical species near the surface of a catalyst, including the gas phase reaction products, in situ, i.e. while the reaction takes place. 
Elemental copper can be used as an unsupported catalyst for the oxidative dehydrogenation of alcohols to their respective aldehydes. In this work the oxidation of methanol is investigated as a model reaction. There are two main reaction paths: partial oxidation to formaldehyde, and total oxidation, which is thermodynamically favored:

$$
\begin{gathered}
\mathrm{CH}_{3} \mathrm{OH}+{ }^{1} / 2 \mathrm{O}_{2} \rightarrow \mathrm{CH}_{2} \mathrm{O}+\mathrm{H}_{2} \mathrm{O} \text { (partial oxidation) } \\
\Delta \mathrm{H}=-159 \mathrm{~kJ} / \mathrm{mol} \\
\mathrm{CH}_{3} \mathrm{OH}+{ }^{3} / 2 \mathrm{O}_{2} \rightarrow \mathrm{CO}_{2}+2 \mathrm{H}_{2} \mathrm{O} \quad \text { (total oxidation) } \\
\Delta \mathrm{H}=-674 \mathrm{~kJ} / \mathrm{mol}
\end{gathered}
$$

Room temperature UHV-XPS studies showed the presence of a methoxy $\left(\mathrm{CH}_{3} \mathrm{O}\right)$ intermediate at the copper surface.[19,20] It was found that methanol reacted with preadsorbed oxygen $\left(\mathrm{O}_{\text {ads }}\right)$ on $\mathrm{Cu}(110)$ and polycrystalline $\mathrm{Cu}$ to methoxy. The methoxy species then decomposes either to formaldehyde, which desorbs from the surface, or is oxidized to formate $(\mathrm{CHOO})$ that is stable at room temperature, but decomposes at $100{ }^{\circ} \mathrm{C}$ to $\mathrm{CO}_{2}$ and $\mathrm{H}_{2}$.[19] In situ near-edge X-ray absorption fine structure (NEXAFS) experiments at the Oxygen $K$-edge were performed at temperatures up to $400{ }^{\circ} \mathrm{C}$ in different methanol-to-oxygen reactant streams at a total pressure of about 1 mbar.[12] These studies showed that the formaldehyde yield is correlated to the presence of a suboxide species at the sample surface that could only be detected under in situ conditions. The NEXAFS results also showed that the catalytically active phase is metallic. In a recent in situ XPS study of the methanol oxidation on polycrystalline $\mathrm{Cu}$ the authors found under reaction conditions a $\mathrm{O} 1 \mathrm{~s}$ peak at $531 \mathrm{eV}$, which they ascribed to the suboxide phase.[16] Contrary to the in situ NEXAFS experiments, however, where the formaldehyde yield correlated positively with the abundance of suboxide,[12] the abundance of the $531 \mathrm{eV}$ species in the in situ XPS experiments decreased with increasing formaldehyde yield. This discrepancy might be due to the fact that the in situ NEXAFS measurement in Ref. 12 were performed under steady-state conditions, while the in situ XPS data in Ref. 16 where measured during the heating of the sample $(0.2 \mathrm{~K} / \mathrm{min})$, i.e. not under steady-state conditions.

In the experiments presented in this article we have used the advantages of synchrotron-based in situ XPS to quantitatively determine the depth-dependent composition of the surface and near-surface region, to a depth of a few nanometers, during the catalytic reaction. We have also investigated the presence of intermediates of the reaction at the catalytically active surface. From our measurements we will show that there is a correlation between the presence of a sub-surface oxygen species, and the formation of formaldehyde in the catalytic reaction.

\section{Experimental}

The experiments were performed at beamline U49/2PGM1 at BESSY in Berlin [21], and at beamline 9.3.2 at the Advanced Light Source in Berkeley [22]. The overall spectral resolution was $0.1 \mathrm{eV}$ at the Oxygen $K$-edge. All spectra were normalized by the incident photon flux, which was measured using a photodiode with known quantum efficiency. The methanol vapor and oxygen flows into the experimental cell were regulated using calibrated mass flow controllers. The combined methanol and oxygen pressure in the experimental cell was 0.6 mbar at a total flow rate of $\sim 10 \mathrm{sccm}$. The sample was a polycrystalline $\mathrm{Cu}$ foil ( $99.99 \%$ purity) mounted on a temperature-controlled heating stage.

XPS experiments at elevated pressures are facing two obstacles: (a) the elastic and inelastic scattering of electrons by gas phase molecules, and (b) the need for high-vacuum conditions for the operation of electron detectors. We have overcome these problems in our experimental setup by using a combination of differential pumping and electrostatic focusing of the emitted photoelectrons.[17] The sample is mounted inside a high-pressure cell $2 \mathrm{~mm}$ away from a small aperture (1 $\mathrm{mm}$ diameter), which is the entrance to a differentially pumped electrostatic lens system (see Fig. 1). Electrons from the sample as well as gas phase molecules escape through this aperture into the first stage of an electrostatic lens system. The electrons are then subsequently focused onto two more apertures (diameters 2 $\mathrm{mm}$ ) that are separated by another electrostatic lens unit before they enter the hemispherical analyser [23]. The combination of electrostatic lenses and differentially pumped apertures allows us to collect electrons with a similar efficiency as a conventional hemispherical analyzer, while keeping a pressure differential of nine orders of magnitude between the high-pressure cell and the hemispherical analyzer.

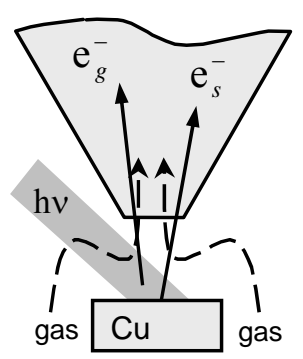

Figure 1: Close-up of the sample-first aperture-geometry. The incident X-rays irradiate the sample under an angle of $55^{\circ}$ from the surface normal. The electrons are detected under normal emission. The incident X-rays do not only irradiate the sample surface (photoelectrons $\mathrm{e}_{\mathrm{s}}^{-}$), but also part of the gas phase in front of the sample (photoelectrons $\mathrm{e}_{\mathrm{g}}{ }^{-}$), which gives rise to gas phase peaks in the in situ XPS spectra. The aperture diameter was $1 \mathrm{~mm}$, the sampleaperture distance $2 \mathrm{~mm}$. 

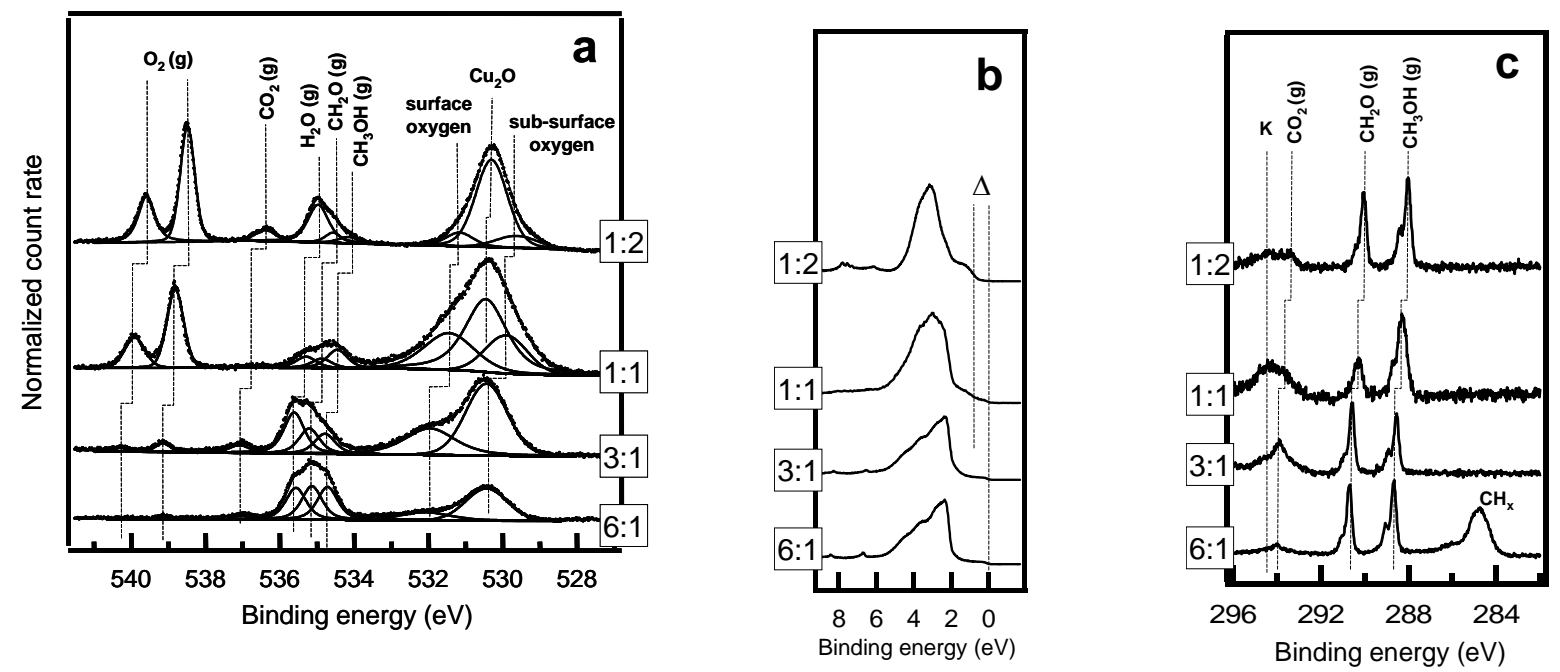

Figure 2: (a) $\mathrm{O} 1 s$ photoelectron spectra of a copper sample at $400{ }^{\circ} \mathrm{C}$ in $\mathrm{CH}_{3} \mathrm{OH}: \mathrm{O}_{2}$ reactant streams of 1:2, 1:1, 3:1, and 6:1. Raw data are shown as dots, the result of the fits as solid black lines. The incident photon energy was $720 \mathrm{eV}$. Gas phase peaks are found at $\mathrm{BEs}>534 \mathrm{eV}$, the surface peaks are at $\mathrm{BE}<534 \mathrm{eV}$. In $\mathrm{CH}_{3} \mathrm{OH}: \mathrm{O}_{2}=1: 2$ and 1:1 the $\mathrm{Cu}_{2} \mathrm{O}$ peak dominates the surface XPS spectrum. The $\mathrm{Cu}_{2} \mathrm{O}$ peak is absent in the spectra that were taken under reducing conditions $\left(\mathrm{CH}_{3} \mathrm{OH}: \mathrm{O}_{2}=3: 1,6: 1\right)$. In those spectra the sub-surface oxygen peak is the strongest peak in the surface part of the spectrum. (b) Corresponding valence band spectra. The spectrum taken in oxidizing conditions $\left(\mathrm{CH}_{3} \mathrm{OH}: \mathrm{O}_{2}=1: 2\right)$ shows a typical shape for a $\mathrm{Cu}_{2} \mathrm{O}$ sample with a gap $\Delta$ at $0.9 \mathrm{eV}$ BE, thus confirming the observation from the $\mathrm{O} 1 \mathrm{~s}$ spectrum in (a). The spectrum taken in $\mathrm{CH}_{3} \mathrm{OH}: \mathrm{O}_{2}=1: 1$ shows that the surface consists of a mixture of metallic copper and $\mathrm{Cu}_{2} \mathrm{O}$. The spectra measured under reducing conditions $\left(\mathrm{CH}_{3} \mathrm{OH}: \mathrm{O}_{2}=3: 1\right.$, 6:1) exhibit the typical valence band spectrum for metallic $\mathrm{Cu}$, which confirms the absence of a $\mathrm{Cu}_{2} \mathrm{O}$ peak in the $\mathrm{O} 1 \mathrm{~s}$ spectra in (a). (c) $\mathrm{C} 1 \mathrm{~s}$ spectra taken under the same conditions as in (a) and (b). $\mathrm{CO}_{2}, \mathrm{CH}_{3} \mathrm{OH}$ and $\mathrm{CH}_{2} \mathrm{O}$ gas phase peaks are observed. There are no carbon-containing species at the surface, only for $\mathrm{CH}_{3} \mathrm{OH}: \mathrm{O}_{2}=6: 1$ a peak is visible at $284.7 \mathrm{eV}$, probably due to decomposition products of methanol that accumulate at the surface. The peak at $294.3 \mathrm{eV}$ is due to some potassium contamination.

Table 1: Partial pressures of methanol, formaldehyde and carbon dioxide as a function of the mixing ratio of oxygen and methanol at $400{ }^{\circ} \mathrm{C}$. The values are calculated from the gas phase peak areas measured using XPS. The methanol conversion $(=1-$ $\left(\mathrm{p}_{\mathrm{CH} 3 \mathrm{OH}}(\mathrm{T}) / \mathrm{p}_{\mathrm{CH} 3 \mathrm{OH}}\left(25^{\circ} \mathrm{C}\right)\right)$, formaldehyde yield $\left(=\mathrm{p}_{\mathrm{CH} 2 \mathrm{O}}(\mathrm{T}) / \mathrm{p}_{\mathrm{CH} 3 \mathrm{OH}}\left(25^{\circ} \mathrm{C}\right)\right)$ and carbon dioxide yield $\left(=\mathrm{p}_{\mathrm{CO} 2}(\mathrm{~T}) / \mathrm{p}_{\mathrm{CH} 3 \mathrm{OH}}\left(25^{\circ} \mathrm{C}\right)\right)$ are also given.

\begin{tabular}{|l|l|l|l|l|l|l|}
\hline $\begin{array}{l}\mathrm{CH}_{3} \mathrm{OH}: \mathrm{O}_{2} \\
\text { mixing ra- } \\
\text { tio }\end{array}$ & $\begin{array}{l}\mathrm{CH}_{3} \mathrm{OH} \\
\text { part. press. } \\
\text { (mbar) }\end{array}$ & $\begin{array}{l}\mathrm{CH}_{2} \mathrm{O} \\
\text { part. press. } \\
\text { (mbar) }\end{array}$ & $\begin{array}{l}\mathrm{CO}_{2} \\
\text { part. press. } \\
\text { (mbar) }\end{array}$ & $\begin{array}{l}\mathrm{CH}_{3} \mathrm{OH} \\
\text { conversion }\end{array}$ & $\begin{array}{l}\mathrm{CH}_{2} \mathrm{O} \\
\text { yield }\end{array}$ & yield \\
\hline $1: 2$ & 0.053 & 0.075 & 0.072 & 0.73 & 0.37 & 0.36 \\
\hline $1: 1$ & 0.173 & 0.070 & 0.027 & 0.36 & 0.26 & 0.10 \\
\hline $3: 1$ & 0.167 & 0.179 & 0.103 & 0.63 & 0.40 & 0.23 \\
\hline $6: 1$ & 0.307 & 0.173 & 0.030 & 0.40 & 0.34 & 0.06 \\
\hline
\end{tabular}

\section{Results and discussion}

We have recorded $\mathrm{O} 1 s$, valence band, $\mathrm{C} 1 s, \mathrm{Cu} 3 p$, and $\mathrm{Cu} 2 p$ photoelectron spectra under different conditions: at a fixed methanol-to-oxygen mixing ratio of 3:1 at temperatures from 25 to $450{ }^{\circ} \mathrm{C}$, and at a fixed temperature $\left(400{ }^{\circ} \mathrm{C}\right)$ in varying methanol-to-oxygen mixing ratios. In this article we will present the data of the mixing ratio series.

Figure 2a shows the O1s region of photoemission spectra of the $\mathrm{Cu}$ catalyst at an incident photon energy of $720 \mathrm{eV}$. The four spectra correspond to methanol-tooxygen mixing ratios in the reactant stream of $1: 2,1: 1,3: 1$, and $6: 1$, and a sample temperature of $400{ }^{\circ} \mathrm{C}$. Since the incident X-ray beam does not only irradiate the sample surface but also the gas phase molecules in front of the 
sample (see Fig. 1), the spectra show gas phase peaks alongside the surface peaks. The binding energy (BE) scale in Fig. 2 is referenced to the Fermi level of the $\mathrm{Cu}$ sample, and therefore the apparent BEs of the gas phase peaks are shifted by the amount of the work function of the sample $(\sim 4.5 \mathrm{eV})$ relative to literature values, which are conventionally referenced to the vacuum level. In Fig. 2a peaks with a $\mathrm{BE}$ higher than $534 \mathrm{eV}$ are due to gas phase species, whereas the peaks with a BE smaller than $534 \mathrm{eV}$ are due to oxygen species at the surface. The spectra show a strong dependence on the chemical composition of the reactant stream. Gas phase peaks of all reactants and products in the reactions (1) and (2) (see above) can be distinguished in the spectra. The $\mathrm{O}_{2}$ gas phase peaks $[24,25]$ are strongest for the $\mathrm{O}_{2}$-rich reaction mixture $\left(\mathrm{CH}_{3} \mathrm{OH}: \mathrm{O}_{2}=1: 2\right)$, and weakest for the most methanol-rich mixture $\left(\mathrm{CH}_{3} \mathrm{OH}: \mathrm{O}_{2}=6: 1\right)$. The catalytic activity of the copper foil in the four different gas mixtures can be calculated from both the areas of the O1s and C1s peaks, as well as from mass spectrometry data. The results are summarized in Table 1. The absolute amount of formaldehyde produced in the catalytic reaction is highest for the $\mathrm{CH}_{3} \mathrm{OH}: \mathrm{O}_{2}=3: 1$ mixing ratio.

The key question in catalysis is of course, how the catalytic reaction depends on the nature of the gas-solid interface, i.e. which species at the catalyst surface are responsible for the catalytic activity. Under our reaction conditions we can distinguish three species at the surface or in the near-surface region under oxidizing $\left(\mathrm{CH}_{3} \mathrm{OH}: \mathrm{O}_{2}=1: 2\right.$, $1: 1)$, and two species under reducing $\left(\mathrm{CH}_{3} \mathrm{OH}: \mathrm{O}_{2}=3: 1,6: 1\right)$ conditions.

In the $\mathrm{CH}_{3} \mathrm{OH}: \mathrm{O}_{2}=1: 2$ mixture a peak with a $\mathrm{BE}$ of $530.3 \mathrm{eV}$ (FWHM $1.0 \mathrm{eV}$ ) dominated the spectrum. This peak is due to $\mathrm{Cu}_{2} \mathrm{O}$, which was confirmed by comparison to the spectrum of $\mathrm{Cu}_{2} \mathrm{O}$ reference sample that was prepared in a separate experiment. The $\mathrm{BE}$ of this peak was also in good agreement with literature values for $\mathrm{Cu}_{2} \mathrm{O}$ which vary from 530.2 to $530.5 \mathrm{eV}$ (for a compilation of $\mathrm{BE}$ values for the copper oxides see Ref.[26]). In addition, the valence band spectrum taken right after the O1s spectrum (Fig. 2b, at a photon energy of $262 \mathrm{eV}$, i.e. the same probing depth as for the $\mathrm{O} 1 \mathrm{~s}$ spectra) also shows a typical $\mathrm{Cu}_{2} \mathrm{O}$ spectrum, in agreement with literature spectra [26] and our $\mathrm{Cu}_{2} \mathrm{O}$ reference spectrum. Two smaller peaks at BEs of $529.7 \mathrm{eV}$ (FWHM $1.3 \mathrm{eV}$ ) and $531.2 \mathrm{eV}$ (FWHM $1.6 \mathrm{eV}$ ) were also present under oxidizing conditions.

When the ratio of methanol to oxygen in the reactant stream was changed to $1: 1$, the relative intensity of the $\mathrm{Cu}_{2} \mathrm{O}$ peak decreased with respect to the two other peaks. The binding energies changed to $530.4 \mathrm{eV}$ for the $\mathrm{Cu}_{2} \mathrm{O}$ peak, and $529.9 \mathrm{eV}$ and $531.4 \mathrm{eV}$ for the other two peaks. The valence band spectrum now shows that the surface is covered both by $\mathrm{Cu}_{2} \mathrm{O}$ and metallic areas. This is evident from the gap $\Delta$ at $0.9 \mathrm{eV} \mathrm{BE}$ which is characteristic for $\mathrm{Cu}_{2} \mathrm{O}$, and the non-zero intensity at the Fermi edge which is characteristic for a metallic surface. The shape of the spectrum also resembles a mixture of the pure metallic and the pure $\mathrm{Cu}_{2} \mathrm{O}$ spectrum.
When the sample was measured under reducing conditions $\left(\mathrm{CH}_{3} \mathrm{OH}: \mathrm{O}_{2}=3: 1,6: 1\right)$, the valence band spectra showed clearly that the surface is metallic, since they exhibited the characteristic spectrum for metallic copper.[27] In the $\mathrm{O} 1 \mathrm{~s}$ region two peaks with $\mathrm{BEs}$ of $530.4 \mathrm{eV}$ and $532.0 \mathrm{eV}$ dominated the spectra. Since the valence band spectra show that the surface is metallic, the peak at 530.4 eV can not be due to $\mathrm{Cu}_{2} \mathrm{O}$.

We will now turn our attention to the $\mathrm{C} 1 \mathrm{~s}$ spectra in order to find out whether the peaks at $530.4 \mathrm{eV}$ and 532.0 $\mathrm{eV}$ in the $\mathrm{CH}_{3} \mathrm{OH}: \mathrm{O}_{2}=3: 1$ and $6: 1 \mathrm{O} 1 \mathrm{~s}$ spectra are caused by oxygen-carbon compounds. Like the $\mathrm{O} 1 \mathrm{~s}$ spectra in Fig. 2a the $\mathrm{C} 1 \mathrm{~s}$ spectra in Fig. 2c show the gas phase peaks of $\mathrm{CO}_{2}, \mathrm{CH}_{2} \mathrm{O}$, and $\mathrm{CH}_{3} \mathrm{OH}$. We do not, however, observe any of the likely intermediates of the methanol oxidation reaction, like methoxy (BE 285.2 eV)[19] or formate (BE $287.7 \mathrm{eV}$ )[19]. We do also not observe any other surface carbon species (the $\mathrm{BE}$ of the $\mathrm{C} 1$ s lines of $\mathrm{C}-\mathrm{H}-\mathrm{O}$ compounds range from 284 to $293 \mathrm{eV}$ ). [28] Since the elemental detection limit in XPS is on the order of $2 \%$ [29], we can conclude that, if intermediates are present at the surface, their concentration must be below that value. Only under the most methanol-rich condition $\left(\mathrm{CH}_{3} \mathrm{OH}: \mathrm{O}_{2}=6: 1\right)$ there is a peak at $284.7 \mathrm{eV}$ with a smaller shoulder at $286.2 \mathrm{eV}$. Those peaks are probably caused by decomposition products of methanol on the hot copper surface. From the known $\mathrm{O} 1 \mathrm{~s} / \mathrm{C} 1 \mathrm{~s}$ detection sensitivity in our experiment we can estimate that if the $284.7 \mathrm{eV}$ peak would be due to a C$\mathrm{O}$ compound with a $\mathrm{C}: \mathrm{O}$ ratio of 1 , its $\mathrm{O} 1 \mathrm{~s}$ peak would have a peak area similar to the $530.4 \mathrm{eV}$ peak in the $\mathrm{CH}_{3} \mathrm{OH}: \mathrm{O}_{2}=6: 1 \mathrm{O} 1 \mathrm{~s}$ spectrum. Since there is no additional peak in the $\mathrm{O} 1 \mathrm{~s}$ spectrum at $6: 1$ when compared to the, e.g., $3: 1$ spectrum, the $\mathrm{C} 1 \mathrm{~s}$ peaks in the $6: 1$ spectrum are not likely to be caused by a $\mathrm{C}-\mathrm{O}$ compound, but rather by some $\mathrm{CH}_{\mathrm{x}}$ compound or pure carbon.

In all $\mathrm{C} 1 \mathrm{~s}$ spectra in Fig. 2c some potassium contamination at the surface can be observed $\left(\mathrm{K} 2 p_{3 / 2}\right.$ at $294.3 \mathrm{eV})$. The influence of the $\mathrm{K}$ contamination on our results seems to be negligible, since we did not find a correlation of the amount of $\mathrm{K}$ at the surface with the catalytic activity. The maximum amount of potassium at the surface was estimated to be $<5 \%$ of the total amount of oxygen at all times.

The nature of the $\mathrm{O} 1 \mathrm{~s}$ peaks at $\mathrm{BE} 530.4 \mathrm{eV}$ and $532.0 \mathrm{eV}$ under reducing conditions (see Fig. 2a) was investigated using depth-profiling by variation of the incident photon energy. Because the mean free path of an electron in a solid depends on its kinetic energy $K E$, the escape depth of the photoelectrons varies with the incident photon energy $h v$, since $K E=h v-B E-\Phi$ (where $\Phi$ is the work function).[30] We have recorded $\mathrm{O} 1 \mathrm{~s}$ spectra at four different incident photon energies: $720 \mathrm{eV}, 890 \mathrm{eV}, 1050 \mathrm{eV}$, and $1300 \mathrm{eV}$ (see Fig. 3a). These photon energies correspond to mean free path lengths of $6 \AA, 8 \AA, 10 \AA$, and $13 \AA$, respectively (assuming predominantly copper in the nearsurface region).[31] 

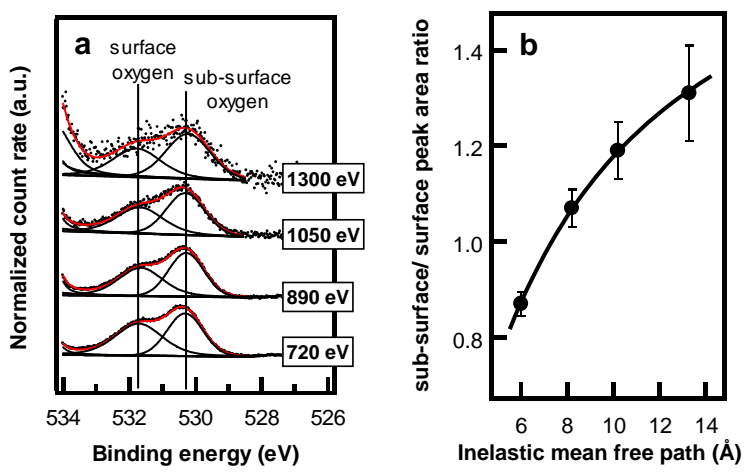

Figure 3: (a) $\mathrm{O} 1 \mathrm{~s}$ spectra as a function of incident photon energy in $\mathrm{CH}_{3} \mathrm{OH}: \mathrm{O}_{2}=3: 1$ at $400{ }^{\circ} \mathrm{C}$. The incident photon energy is indicated for each spectrum. In the fits of the peaks their relative BE position was kept constant, as well as the ratio of their FWHM. The FWHM ratio was kept constant instead of the absolute values to account for the decrease of the spectral resolution with increasing incident photon energy, which leads to a broadening of the peaks. (b) Peak area ratio of the sub-surface oxygen $(530.4 \mathrm{eV})$ and surface oxygen $(532.0 \mathrm{eV}) \mathrm{O} 1 \mathrm{~s}$ peaks calculated from the peak areas in (a). The relative increase of the spectral weight of the $530.4 \mathrm{eV}$ peak with increasing inelastic mean free path indicates that this species is located below the $532.0 \mathrm{eV}$ species, in the sub-surface region. The spacing between neighboring atomic layers in $\mathrm{Cu}$ in the [100] direction is $1.8 \AA$. The solid line is a least squares fit of the data points using $I_{530.4} / I_{532.0}=n_{530.4} / n_{532.0} \cdot \exp \left[-\left(z_{532.0}-Z_{530.4}\right) / \quad\right.$, with $I$ as integrated intensity of the peak, $n$ the concentration in atom percent, $z$ the average depth below the surface, and the inelastic mean free path. The fit parameters are $n_{530.4} / n_{532.0}=1.8$, and $\mathrm{z}_{532.0}-\mathrm{Z}_{530.4}=4 \AA$.

The depth-profiling measurements revealed that the $532.0 \mathrm{eV}$ peak intensity decreased with respect to the 530.4 $\mathrm{eV}$ peak intensity with increasing mean free path length (see Fig. 3b). This implies that the $532.0 \mathrm{eV}$ species is located at the surface, while the $530.4 \mathrm{eV}$ species extends into the sub-surface region. The fit of the data points in Fig. $3 b$ yields an average separation of $4 \AA$ of the two species in the direction perpendicular to the surface. This average value does not give information about the actual depth distribution of the two species, but it confirms that the $530.4 \mathrm{eV}$ species has to be located below, or at least be embedded in the surface. The exact nature of the surface peak at $532.0 \mathrm{eV}$ is not clear. Its $\mathrm{BE}$ fits that of an $\mathrm{OH}^{-}$ species [32], but it could as well be caused by oxygen bound by residual impurities at the copper surface. It is noteworthy that this peak did not show any correlation to the catalytic activity of the sample, and could also be observed under high-vacuum conditions. A recent in situ XPS study of the methanol oxidation on copper did also find two peaks at the O1s edge under reaction conditions with BEs similar to our surface peaks.[16] The authors of this study assigned the low BE peak $(529.8 \mathrm{eV})$ to adsorbed oxygen, and the peak at $531.2 \mathrm{eV}$ to a suboxide species. This assignment can not be made for the peaks in Fig. 2a that are observed under reducing conditions, since the depth-profiling data in Fig. $3 \mathrm{~b}$ show that the low-BE species is located below the surface and can therefore not be assigned to adsorbed oxygen.

In the previous discussion we have shown that the peak at $530.4 \mathrm{eV}$ under reducing conditions is due to subsurface oxygen, which could be in the form of a sub-oxide as discussed in Ref.[12], oxygen "rafts" below the surface as proposed for the case of $\mathrm{Ru}$ [33], or due to oxygen located at grain boundaries in the polycrystalline copper sample. The sub-surface oxygen peak could only be observed in in situ measurements. When the oxygen flow to the cell was stopped, the sub-surface oxygen peak vanished in less than one second. We can estimate the average concentration of sub-surface oxygen as a function of depth from the surface. To that end the O1s peak area of the subsurface oxygen peak measured at different photoelectron mean free path lengths was compared to the $\mathrm{Cu} 3 p$ peak area measured at the same mean free path lengths. The $\mathrm{BE}$ of $\mathrm{Cu} 3 p_{1 / 2}$ and $\mathrm{Cu} 3 p_{3 / 2}$ is $77.3 \mathrm{eV}$ and $75.1 \mathrm{eV}$, respectively. Cu3p spectra were taken at incident beam energies of $262 \mathrm{eV}, 432 \mathrm{eV}, 582 \mathrm{eV}$, and $842 \mathrm{eV}$.[34] The O:Cu stoichiometry was then calculated from the $\mathrm{O} 1 s$ and $\mathrm{Cu} 3 p$ peak areas at similar KE, after correcting for the energydependent changes of the photoemission cross-sections for $\mathrm{Cu} 3 p$ and O1s.[35]
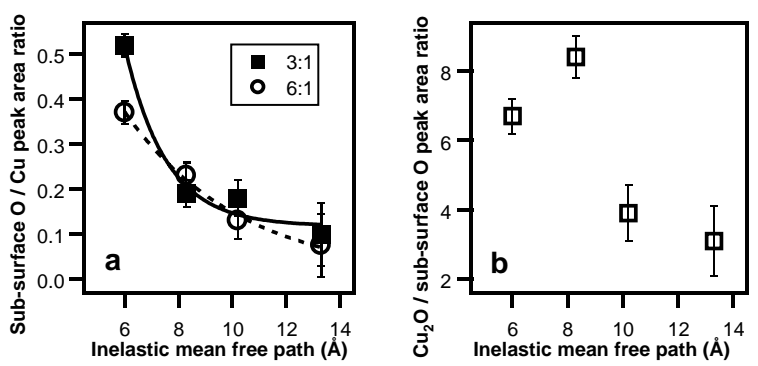

Figure 4: (a) Sub-surface O-to-Cu stoichiometry under reducing conditions as a function of the inelastic mean free path of the photoelectrons. The concentration of subsurface oxygen close to the sample surface is higher for the oxygen-rich atmosphere $\left(\mathrm{CH}_{3} \mathrm{OH}: \mathrm{O}_{2}=3: 1\right)$. Deeper into the sample the concentration of sub-surface oxygen is similar for the two different atmospheres. (b) Sub-surface oxygento- $\mathrm{Cu}_{2} \mathrm{O}$ peak area ratio as a function of the inelastic mean free path of the photoelectrons under oxidizing conditions $\left(\mathrm{CH}_{3} \mathrm{OH}: \mathrm{O}_{2}=1: 2\right) . \quad \mathrm{Cu}_{2} \mathrm{O}$ is predominantly located at the sample surface.

The results for the active catalyst surface shown in Fig. $4 \mathrm{a}$ indicate that there is an oxygen concentration gradient perpendicular to the surface. In both reducing gas atmospheres, the concentration of sub-surface oxygen is highest close to the surface, and decreases below the surface, which is in agreement with the $\Delta \mathrm{z}$ value from the fit in Fig. 3b. At our largest probing depth of $15 \AA$ the $\mathrm{Cu}: \mathrm{O}$ stoichiometry is about 10 , similar to the value found in in 
situ NEXAFS experiments of the methanol oxidation on a $\mathrm{Cu}$ foil under the same reaction conditions.[36] Those NEXAFS experiments were performed in the total electron yield detection mode where the probing depth is estimated to be 20 A, i.e. similar to the largest probing depth in our experiments.[37]

It is also noteworthy that in the case of $\mathrm{CH}_{3} \mathrm{OH}: \mathrm{O}_{2}=3: 1$ the $\mathrm{O}: \mathrm{Cu}$ stoichiometry close to the surface is similar to that of $\mathrm{Cu}_{2} \mathrm{O}$. The valence band spectra in Fig. $2 \mathrm{~b}$, however, have shown that even at such an oxygen concentration the sample surface region has still a metallic character. This is also in good agreement with the above mentioned in situ NEXAFS measurements where the $\mathrm{O} K$ edge and $\mathrm{Cu} L$ edge spectra of the catalytically active surface under reducing conditions showed no resemblance to the spectra of either of the stoichiometric copper oxides $\mathrm{Cu}_{2} \mathrm{O}$ and $\mathrm{CuO}$.[36]

We have also performed depth-profiling on the copper surface under oxidizing conditions $\left(\mathrm{CH}_{3} \mathrm{OH}: \mathrm{O}_{2}=1: 2\right)$. In Fig. $4 \mathrm{~b}$ the ratio of the peak areas of the peak at 529.7 $\mathrm{eV}$ vs. the $\mathrm{Cu}_{2} \mathrm{O}$ peak are shown. Fig $4 \mathrm{~b}$ is consistent with a surface mostly covered by a $\mathrm{Cu}_{2} \mathrm{O}$ layer with the 529.7 $\mathrm{eV}$ oxygen species below. This indicates that the peak at $529.7 \mathrm{eV}$ under oxidizing conditions is most likely also caused by sub-surface oxygen, similar to the peak at 530.4 $\mathrm{eV}$ under reducing conditions, even though the BEs of the two peaks are different. In other in situ XPS experiments of the methanol oxidation on copper we have observed that the BE of the sub-surface species can vary between 529.7 $\mathrm{eV}$ and $530.5 \mathrm{eV}$, depending on the exposure time of the $\mathrm{Cu}$ sample to the reaction mixture and the presence of other oxygen species at the surface. Variations in the faceting of the polycrystalline $\mathrm{Cu}$ surface might contribute to the variations in the BE of the sub-surface species. The BE of the high-BE surface species in Fig. 2a also shifts by about the same amount as the sub-surface oxygen peak.

From Fig. 2a it is evident that the BEs of the gas phase peaks shift in the same direction as the BE of the surface peaks when going from oxidizing to reducing conditions. Unlike the shift of the surface peaks, the gas phase peak shifts are caused by a change of the work function of the sample surface upon reduction. Changes of the sample work function have an influence on the gas phase peak positions, since the vacuum level of the gas phase molecules depends on the work function of the surrounding surfaces.[38] When a clean metallic $\mathrm{Cu}$ surface is oxidized to $\mathrm{Cu}_{2} \mathrm{O}$, its work function increases by about 0.3 eV.[39,40] An increase in the sample work function increases the kinetic energy of the gas phase photoelectrons, and therefore decreases their apparent $\mathrm{BE}$ when the $\mathrm{BE}$ scale is referenced to the Fermi energy of the sample, as it is done in our case.[41] The apparent shift of the BE of the gas phase species in the measurement of the oxidized and the metallic sample in Fig. $2 \mathrm{a}$ is $+0.5 \mathrm{eV}$, i.e. on the order of the work function change measured during the oxidation of $\mathrm{Cu}$ to $\mathrm{Cu}_{2} \mathrm{O}$.

In order to find a relation between the catalytic activity of the sample and the state of its surface, we have to compare the abundance of the surface species with the formaldehyde yield. Figure 5 shows the dependence of the $\mathrm{CH}_{2} \mathrm{O}$ partial pressure on the abundance of sub-surface oxygen in the sample (expressed in terms of its peak area) for the four $\mathrm{CH}_{3} \mathrm{OH}: \mathrm{O}_{2}$ mixing ratios, and also for a separate experiment were the $\mathrm{CH}_{3} \mathrm{OH}: \mathrm{O}_{2}$ mixing ratio was kept constant at 3:1, but the temperature was varied in the range from $150{ }^{\circ} \mathrm{C}$ to $450{ }^{\circ} \mathrm{C}$. There is a linear correlation between the abundance of sub-surface oxygen and the yield of $\mathrm{CH}_{2} \mathrm{O}$, in good agreement with in situ NEXAFS data.[46] Fig. 5 does also show that in the absence of subsurface oxygen, there is no catalytic activity towards the partial oxidation of methanol.

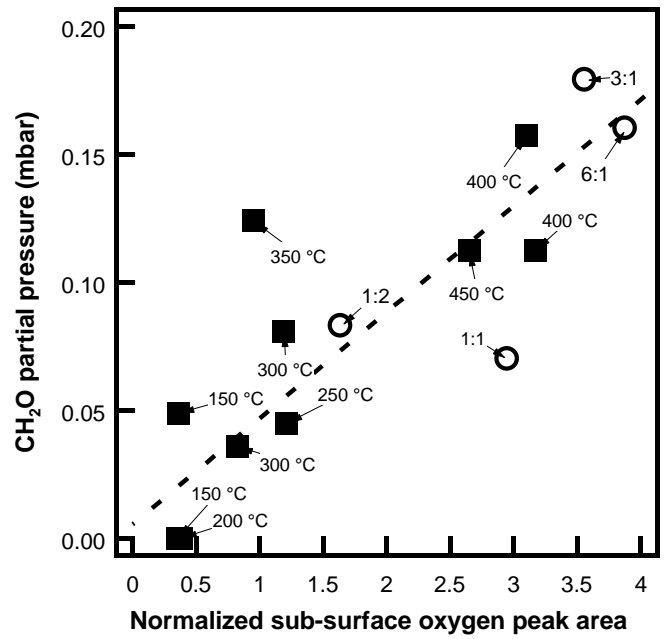

Figure 5: Partial pressure of formaldehyde as a function of the sub-surface oxygen peak area for the spectra in Fig. 1a (open circles), and for a different experiment (black squares) in which the temperature was varied in the range from $150{ }^{\circ} \mathrm{C}$ to $450{ }^{\circ} \mathrm{C}$ at a constant $\mathrm{CH}_{3} \mathrm{OH}: \mathrm{O}_{2}$ mixing ratio of 3:1 (the same total pressure as for the spectra in Fig 1a). The partial pressure of formaldehyde is linearly correlated to the abundance of sub-surface oxygen in the nearsurface region. The dashed line is a linear fit of the data points.

Having thus proved that the copper catalyst has to contain sub-surface oxygen to be active in the partial oxidation of methanol it remains to be seen what role this species plays in the reaction. Its role could be of a direct nature, for example by emerging to the surface in a favourable energetic state and geometry, similar to what has been observed in the hydrogenation of ethylene $\left(\mathrm{C}_{2} \mathrm{H}_{4}\right)$ on nickel surfaces, where ethylene reacts with sub-surface hydrogen to form ethane $\left(\mathrm{C}_{2} \mathrm{H}_{6}\right)$. [2,42,43] Sub-surface oxygen could also be indirectly involved in the methanol oxidation, via modification of the copper electronic structure, as shown in recent studies of the methanol synthesis reaction on binary $\mathrm{Cu} / \mathrm{ZnO}$ catalysts.[44] In these studies it is argued that strain in the copper surface leads to an increased catalytic activity, as was concluded from density functional calculations that show that strain causes an up-shift of the $d$-band center, which in turn leads to a higher substrate-adsorbateinteraction.[45] The valence band spectra in our experi- 
ments do not show systematic variations of the $d$-band center with the catalytic activity, but the changes that are predicted by the theory are rather small (on the order of 0.1 $\mathrm{eV}$ ) so that we can not exclude this explanation for the increased catalytic activity of the copper sample. We propose that the sub-surface oxygen species that we find in our catalytically active $\mathrm{Cu}$ samples plays the role of a cocatalyst. It is not a reaction partner in the catalytic reaction (unlike $\mathrm{O}_{a d s}$ in the model discussed in Refs.[19] and [20]), but, together with the neighboring $\mathrm{Cu}$ atoms, forms the active center where the reaction takes place.

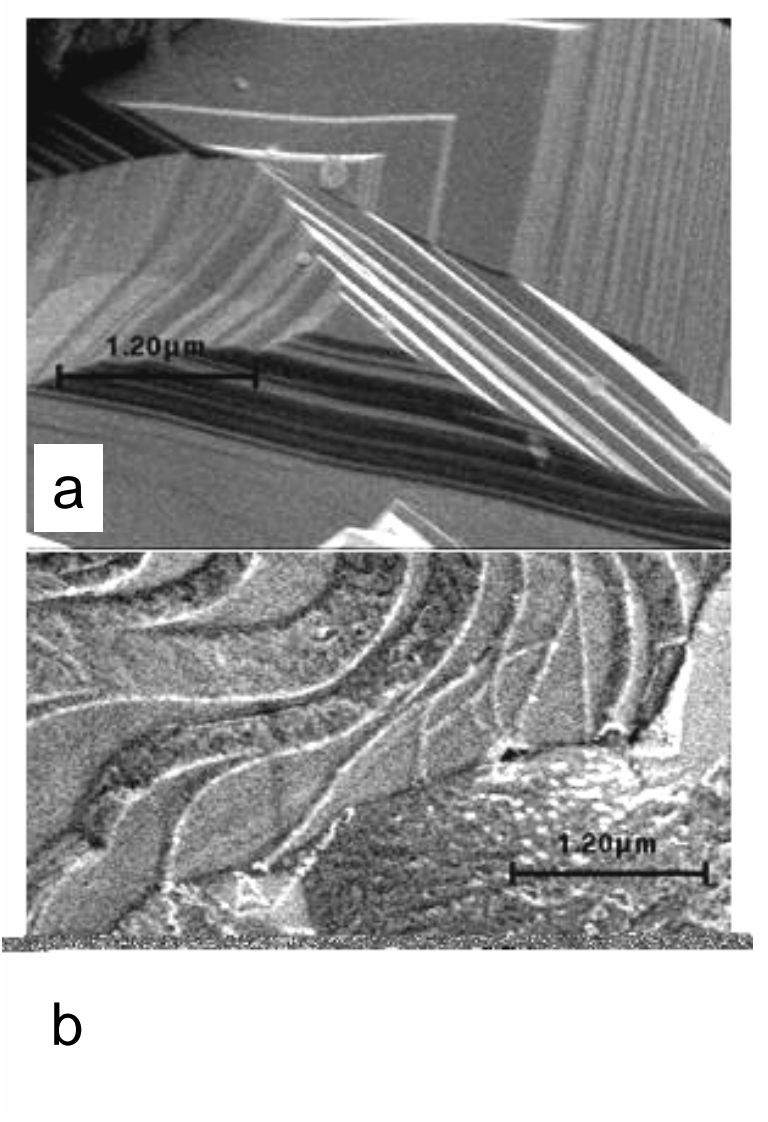

Figure 6: Scanning electron microscopy images of a copper foil that was exposed at $400{ }^{\circ} \mathrm{C}$ to (a) helium, and (b) a $\mathrm{CH}_{3} \mathrm{OH}: \mathrm{O}_{2}=2: 1$ reactant stream. Whereas the surface that was exposed to helium shows predominantly [112] orientation, the surface that was in the reactant stream exhibits both [112] and [111] domains. Electron backscattering diffraction experiments revealed that the smooth areas in (b) have [111] orientation, while the rough ones are [112] oriented. The granular objects are most likely copper oxide particles.

The presence of oxygen species at and below the $\mathrm{Cu}$ surface (as found in our in situ XPS experiments using nondestructive depth profiling) is also supported by scanning electron microscopy (SEM) investigations of the morphology of $\mathrm{Cu}$ foils that were used in atmospheric pressure conversion experiments. At $400{ }^{\circ} \mathrm{C}$ in stoichiometric feed $\left(\mathrm{CH}_{3} \mathrm{OH}: \mathrm{O}_{2}=2: 1\right)$ the $\mathrm{Cu}$ foil reached a steady state performance after 1 hour, with $68 \% \mathrm{CH}_{3} \mathrm{OH}$ conversion and more than $88 \%$ selectivity to formaldehyde. No hydrogen was found in the exit stream, in contrast to the Ag system that produces at higher temperatures a significant amount of hydrogen. In Figure 6 characteristic SEM images of a $\mathrm{Cu}$ foil that was exposed to $\mathrm{He}$ at $400{ }^{\circ} \mathrm{C}$ (Fig. 6a), and a $\mathrm{Cu}$ foil that was exposed to stoichiometric methanol/oxygen feed at $400{ }^{\circ} \mathrm{C}$ (Fig. 6b) are compared. In both cases significant restructuring and roughening in the submicron range has occurred. Using electron backscattering diffraction (EBSD) it was possible to deduce that the preferred surface orientation in the inert gas is [112] (see Fig. $6 a$ ), whereas it is clearly [111] in oxygen / $\mathrm{He}$ (not shown here) and a mixture of the two orientations with a strong predominance of [111] in the feed gas (see Fig. 6b). The low voltage SEM image in Fig. 6b gives a clear impression of the surface roughness and anisotropy of the foil that was exposed to the feed gas, where at least two types of surface orientations coexist. The grain boundaries between differently oriented grains in the untreated foil are retained as sharp boundaries between series of facets. From comparison with the EBSD data it is concluded that the smooth parts of the surface have a [111] orientation, whereas the rough parts are [112] oriented. The granular objects in Fig. $6 \mathrm{~b}$ are most likely copper oxides, since the presence of impurities (such as foreign heavy elements) could be ruled out from point energy dispersive X-ray analysis (EDX) measurements. The presence of oxygen has thus a clear influence on mesoscopic restructuring. From the amount of mass transport that is required to achieve the structuring in Fig. $6 \mathrm{~b}$ it is highly probable that some bulk-dissolved oxygen is involved in the change of the stability of the surface orientation. It should be noted that the size of the small features in Fig. 6b is still two orders of magnitude larger than the depth of information in our XPS experiments.

We now compare our in situ XPS results with the results of UHV-XPS measurements of the methanol oxidation.[19,20] In the UHV-XPS experiments at room temperature different $\mathrm{Cu}$ surfaces [(110), (111), and polycrystalline $\mathrm{Cu}$ ] were predosed with oxygen, which dissociated and adsorbed on the surface. When the oxygenpredosed surface was exposed to methanol, methoxy (the intermediate for formaldehyde formation) was formed on all three surfaces. On $\mathrm{Cu}(110)$ and on polycrystalline $\mathrm{Cu}$ a subsequent reaction of methoxy to formate could be observed, which is assumed to be the intermediate to the total oxidation to $\mathrm{CO}_{2}$. The UHV experiments did also show that formate formation did not occur at $\mathrm{Cu}(111)$ surfaces. These findings are in agreement with early low-energy electron diffraction studies that showed that the (110) surface showed a higher reactivity than the (111) surface.[46,47] From the C1s spectra in Fig 2c it is apparent that the concentration of carbon-containing intermediates of the reaction under our reaction conditions $\left(400{ }^{\circ} \mathrm{C}\right.$ vs. $25^{\circ}$ $\mathrm{C}$ in UHV-XPS studies) has to be below the detection limit of XPS, i.e. below $\sim 2 \%$. This does not mean, however, that methoxy and formate are not possible intermediates under our reaction conditions; if the lifetime of the intermediates at our temperatures is shorter than at room temperature, the concentration of the intermediates at the surface is lower 
compared to the situation in the room temperature UHVXPS investigations.

In a recent microkinetical investigation of the methanol oxidation on silver, the coverage of silver by methoxy, formate, and $\mathrm{O}_{\mathrm{ads}}$ was calculated.[48] For $\mathrm{Ag}$ at $400{ }^{\circ} \mathrm{C}$ in 0.1 mbar of pure oxygen (comparable to the partial pressure of oxygen in our experiments) the authors found a coverage of $\sim 2 \%$ of $\mathrm{O}_{\mathrm{ads}}$ on $\mathrm{Ag}$, i.e. just at the detection limit of XPS. The authors have also calculated the coverage of Ag by $\mathrm{O}_{\text {ads }}$, formate, and methoxy in a gas mixture of $32 \%$ $\mathrm{CH}_{3} \mathrm{OH}, 4.5 \% \mathrm{O}_{2}, 11.6 \% \mathrm{CH}_{2} \mathrm{O}, 1.3 \% \mathrm{CO}_{2}, 7.4 \% \mathrm{H}_{2} \mathrm{O}$, and $6.5 \% \mathrm{H}_{2}$ at a total pressure of $1 \mathrm{~atm}$. It was found that in the temperature range from 100 to $600{ }^{\circ} \mathrm{C} \mathrm{O}_{\mathrm{ads}}$ is the dominating species on the surface, and that its coverage is at least two orders of magnitude higher than that of methoxy and formate. Even though our experiments were performed on $\mathrm{Cu}$, and the total pressure was lower than that used in the calculations, the results of the theoretical modeling might explain the absence of methoxy and formate peaks in the $\mathrm{C} 1 s$ spectra in Fig. 2c. Under our reaction conditions we do not observe $\mathrm{O}_{\text {ads }}$ which has a $\mathrm{BE}$ of $529.8 \mathrm{eV}$ on polycrystalline $\mathrm{Cu}$.[19] The peak at $530.4 \mathrm{eV}$ under reducing conditions, which would be the most likely candidate for $\mathrm{O}_{\mathrm{ads}}$ in our data, is due to sub-surface oxygen (see Fig. 3). Since $\mathrm{O}_{\mathrm{ads}}$ is the dominating species according to the microkinetical model calculations, it is unlikely that methoxy or formate species are detected in our experiments.

Our experimental results may further be compared to theoretical studies of the location of active oxygen species in various metals. The analogy of $\mathrm{Cu}$ to the well-studied silver system [49] has been used already much earlier.[50] The quantitative differences in the geometry of adsorbates are explained in these studies by the differences in the local chemical metal-oxygen bonding. In a series of detailed studies of multiple Ag-O configurations [49,51,52] it is further argued that a general trend in metal oxygen systems exists. When going from low temperatures and high oxygen partial pressures to high temperatures and low oxygen partial pressures a series of transitions should occur, starting from thick oxides over multiple sandwiches of oxygenmetal-oxygen trilayers to a thin surface oxide with metal termination, and finally to a pure metal with surface adsorbates. The relevance of bulk-dissolved or sub-surface oxygen species for catalytic functions was ruled out on grounds of energy arguments. The extent to which such a scenario may be extrapolated between the well-studied systems Ag$\mathrm{O}$ and Ru-O $[53,54]$ may be estimated from the thermodynamic data of the respective heats of formation at the relevant temperatures and at standard pressure (see Table 2).

The data reveal, in agreement with the discussion in Ref.[49], that Ag does not form a "thick" oxide at catalytically relevant temperatures, whereas the other metals do, depending on the partial pressure of oxygen at a given relevant temperature. We therefore assume that the reaction scenario deduced for $\mathrm{Ag}$ is also valid for $\mathrm{Cu}$, taking into consideration that there will be always a tendency to have some oxide present in the system, which is found indeed in the present work.
Table 2:Enthalpies of formation for solid phases of selected oxides (in $\mathrm{kJ} / \mathrm{mol}$ ).

\begin{tabular}{|l|l|l|l|}
\hline$\Delta \mathrm{G}_{\mathrm{f}}$ & $300 \mathrm{~K}$ & $500 \mathrm{~K}$ & $700 \mathrm{~K}$ \\
\hline $\mathrm{Ag}_{2} \mathrm{O}$ & -11 & +2 & ----- \\
\hline $\mathrm{Cu}_{2} \mathrm{O}$ & -148 & -132 & -117 \\
\hline $\mathrm{CuO}$ & -128 & -109 & -92 \\
\hline $\mathrm{RuO}_{2}$ & -252 & -217 & -194 \\
\hline
\end{tabular}

The data in Figs. 2 and 3 imply an agreement with the general scenario, where the oxide-to-metal transition is achieved by the variation of the $\mathrm{CH}_{3} \mathrm{OH}: \mathrm{O}_{2}$ ratio in the feed. This transition is accompanied by a modification of the surface orientation, where a mixture of at least two different terminations with quite different surface structural properties will be present at the surface. Due to this complication it is not possible to quantitatively compare theory and experiment, since the phase diagrams in the literature do not take into account the structure sensitivity of at least the adsorbate phases.

In the case of silver the oxygen-poor phase after the oxide-to-metal transition is a trilayer with oxygen in the hollow sites of a metal terminating layer, and a layer of sub surface oxygen.[55] An arrangement of two trilayers that are stacked together would fill the depth of information that is accessible in our XPS experiments. What is assigned in the present work as sub-surface oxygen may therefore be similar to an arrangement of trilayers in the terminology used in, e.g., Ref. [53]. The approximate stoichiometry of the sub-surface species that is found in our work $\left(\sim \mathrm{Cu}_{2} \mathrm{O}\right)$ would also be consistent with this assignment. Recent in situ NEXAFS experiments [12] showed the same correlation between formaldehyde yield and abundance of a subsurface oxygen species as in our experiments (see Fig. 5). From the NEXAFS results we can conclude that the oxygen in these trilayers would have to be differently bonded to copper than in $\mathrm{Cu}_{2} \mathrm{O}$, with a reduced rehybridisation between oxygen and copper. It remains speculative in the absence of a theoretical model of this system, if oxygen surrounded by metal atoms, or the local geometric variation of the metal-metal interaction caused by the presence of the oxygen are the cause for the catalytic activity of the $\mathrm{Cu}-\mathrm{O}$ trilayer ensemble.

The surface oxygen species in the present work would correlate to the surface adsorbates at undercoordinated metal sites that were identified in the theoretical model of the Ag-O system. This strongly interacting species is not relevant for oxi-dehydrogenation in the $\mathrm{Cu}-\mathrm{O}$ system (no correlation of its abundance to catalytic performance in our experiments). The grain boundaries between facets seen in Figure 6 would form typical locations for this species.

From our in situ XPS experiments it follows that the sub-surface oxygen species forms with no detectable kinetic hindrance. The oxygen is not desorbing but rather 
transforming some $\mathrm{Cu}$ into oxide species [56], similar to the oxide grains in Fig. 6b. The shape of the oxygen profiles (see Fig. 4) further indicates that there is also a constant abundance of oxygen deeper in the bulk. Such oxygen, deemed not relevant for catalysis in the theoretical models [49], may play a crucial role in the generation and stabilization of the necessary defects that enable a fast interchange of sub-surface oxygen between trilayer, adsorbate, and oxide. Its presence would further explain the variation of the peak position of the sub-surface species in XPS (see Fig. 2), which may be caused by a superposition of the signatures of sub-surface and bulk-dissolved species that both do not form strong covalent interactions with the copper $d$-band.

The experimental observation that all $\mathrm{Ag}$ and $\mathrm{Cu}$ catalysts require activation under oxidizing conditions, and the extensive studies of the deactivation of silver due to an increase of the structural perfection of the metal [57] support the view that this metastable, bulk-dissolved oxygen has the role of an enabling species for the facile adaptation of the metal-oxygen system to the structures that are dictated by thermodynamics. In this view the observation that a very small average lattice expansion of $\mathrm{Cu}$ correlates well with the catalytic activity indicates the importance of lattice defects as "exchange sites" for the surface-to-subsurface migration of oxygen species. Since this lattice expansion is below $0.2 \%$ [58] it would also explain why we do not observe a shift of the $\mathrm{Cu} d$-band center in our experiments.

\section{Conclusions}

Our experiments have shown that the active catalyst surface is metallic copper that contains a sub-surface oxygen species. The incorporation of oxygen in the metallic

\section{References}

[1] Somorjai, G. A. Introduction to Surface Chemistry and Catalysis; Wiley\&Sons: New York, 1994.

[2] Ceyer, S. T. Acc. Chem. Res. 2001, 34, 737.

[3] Campbell, C. T. Science 2001, 294, 1471.

[4] Jaeger, N. I. Science 2001, 293, 1601.

[5] Sachs, C.; Hillebrand, M.; Völkening, S.; Wintterlin, J.; Ertl, G. Science 2001, 293, 1635.

[6] McIntyre, B. J.; Salmeron, M.; Somorjai, G.A. Catal. Lett. 1992, 14, 263.

[7] Hansen, T.W.; Wagner, J.B.; Hansen, P.L.; Dahl, S.; Topsøe, H.; Jacobson, C.J.H. Science 2001, 294, 1508.

[8] Hansen, P.L.; Wagner, J.B.; Helvig, S.; Rostrup-Nielsen, J.R.; Clausen, B.S.; Topsøe, H. Science 2002, 295, 2053.

[9] Österlund, L.; Rasmussen, P.B.; Thostrup, P.; Lægsgaard, E.; Stensgaard, I.; Besenbacher, F. Phys. Rev. Lett. 86, 460 (2001).

[10] Hendriksen, B.L.M.; Frenken, J.W.M. Phys. Rev. Lett. 2002, 89, 046101

[11] Dellwig, T.; Rupprechter, G.; Unterhalt, H.; Freund, H.-J. Phys. Rev. Lett. 2000, 85, 776. surface will most likely lead to a strained $\mathrm{Cu}$ surface lattice. We have also determined that the abundance of sub-surface oxygen correlates with the amount of formaldehyde that is produced in the catalytic reaction, and that the pure copper surface would be catalytically inactive in the partial oxidation of methanol to formaldehyde. The truly active surface can only be observed in in situ experiments. Under our experimental conditions $\left(400{ }^{\circ} \mathrm{C}, \mathrm{p}_{\text {total }}=0.6\right.$ mbar $)$ we do not observe any intermediates of the reaction. Our experiments have shown that the catalytic activity of the copper sample is not only determined by its surface properties, but that the chemical composition of the sub-surface region determines the reactivity of the catalyst.

\section{Acknowledgements}

We would like to thank Rolf Follath (Bessy, Berlin) and Ed Wong (ALS, Berkeley) for their help during the measurements. We also thank Gisela Weinberg and HansJörg Wölk (Fritz Haber Institute, Berlin) for providing the SEM images of the $\mathrm{Cu}$ foils. Financial support by the German Research Council (DFG) in the framework of the Brückenschlagsprojekt "Schl. 332/4-1" is gratefully acknowledged. This work was also supported by the Director, Office of Science, Office of Basic Energy Sciences, Division of Materials Sciences and Engineering, of the U.S. Department of Energy under Contract No. DE-AC0376 SF00098.
[12] Knop-Gericke, A.; Hävecker, M.; Schedel-Niedrig, T.; Schlögl, R. Top. Catal. 2001, 15, 27.

[13] Hess, Ch.; Ozensoy, E.; Goodman, D.W. J. Phys. Chem. B 2003, 107, 2759.

[14] Joyner, R.W.; Roberts, M.W.; Yates, K. Surf. Sci. 1979, 87, 501.

[15] Ruppender, H.-J.; Grunze, M.; Kong, C.W.; Wilmers, M. Surf. Interface Anal. 1990, 15, 245.

[16] Bukhtiyarov, V.I.; Prosvirin, I.P.; Tikhomirov, E.P.; Kaichev, V.V.; Sorokin, A.M.; Evstigneev, V.V. React. Kinet. Catal. Lett. 2003, 79, 181.

[17] Ogletree, D.F.; Bluhm, H.; Lebedev, G.; Fadley, C.S.; Hussain, Z.; Salmeron, M. Rev. Sci. Instrum. 2002, 73, 3872.

[18] Bluhm, H.; Ogletree, D.F.; Fadley, C.S.; Hussain, Z.; Salmeron, M. J. Phys.: Condens. Matter 2002, 14, L227.

[19] Carley, A.F.; Owens, A.W.; Rajumon, M.K.; Roberts, M.W.; Jackson, S.D. Catal. Lett. 1996, 37, 79.

[20] Bowker, M.; Madix, R. J. Surf. Sci. 1980, 95, 190.

[21] Sawhney, K.J.S.; Senf, F.; Gudat, W. Nucl. Instrum. Meth. A 2001, 467, 466 . 
[22] Hussain, Z.; Huff, W.R.A.; Kellar, S.A.; Moler, E.J.; Heimann, P.A.; McKinney, W.; Padmore, H.A.; Fadley, C.S.; Shirley, D.A. J. Elect. Spec. Rel. Phenom. 1996, 80, 401.

[23] We have used a modified Phoibos 150 hemispherical analyzer made by SPECS GmbH, Berlin, Germany.

[24] The oxygen gas phase peak is split into two separate peaks due to the paramagnetic nature of the $\mathrm{O}_{2}$ molecule. For a detailed discussion of this effect see Ref. Fehler! Textmarke nicht definiert.

[25] Siegbahn K.; Nordling, C.; Johansson, G.; Hedman, J.; Hedén, P.F.; Hamrin, K.; Gelius, U.; Bergmark, T.; Werme, L.O.; Manne, R.; Baer, Y. ESCA Applied to Free Molecules; North-Holland: Amsterdam, 1969, pp. 56-60.

[26] Ghijsen, J.; Tjeng, L.H.; van Elp, J.; Eskes, H.; Westerink, J.; Sawatzky, G.A.; Czyzyk, M.T. Phys. Rev. B 1988, 38, 11322

[27] Hüfner, S.; Wertheim, G.K.; Wernick, J.H. Phys. Rev. B 1973, 8, 4511.

[28] NIST X-ray Photoelectron Spectroscopy Database, Version 3.4 (Web version); http://srdata.nist.gov/xps/.

[29] McIntyre, N.S.; Chan, T.C.; In Practical Surface Analysis. Vol. 1: Auger and X-ray Phototelectron Spectroscopy, $2^{\text {nd }}$ Edition; Briggs, D.; Seah, M. P., Eds.; Wiley\&Sons: Chichester, 1990, p. 488.

[30] Rivière, J.C.; In Practical Surface Analysis. Vol. 1: Auger and $X$-ray Phototelectron Spectroscopy, $2^{\text {nd }}$ Edition; Briggs, D.; Seah, M. P., Eds.; Wiley\&Sons: Chichester, 1990, p. 52.

[31] Tanuma, S.; Powell, C. J.; Penn, D.R. Surf. Interface Anal. 1991, 17, 911.

[32] Au, Chak-tong; Breza, J.; Roberts, M.W. Chem. Phys. Lett. 1979, 66, 340.

[33] Reuter, K.; Ganduglia-Pirovano, M.V.; Stampfl, C.; Scheffler, M. Phys. Rev. B 2002, 65, 165403.

[34] The gas phase has no influence on the relative detection efficiency of $\mathrm{O} 1 s$ or $\mathrm{Cu} 3 p$ photoelectrons, since we always compare measurements where $\mathrm{O} 1 s$ and $\mathrm{Cu} 3 p$ photoelectrons have the same kinetic energy. On the other hand, the attenuation of the incident photon beam depends on the photon energy which differs for the $\mathrm{Cu} 3 p$ and $\mathrm{O} 1 s$ spectra. In our experiments the beam travels $2 \mathrm{~cm}$ through the gas before it hits the sample. For a gas mixture of $\mathrm{CH}_{3} \mathrm{OH}: \mathrm{O}_{2}=3: 1$ at a total pressure of 0.6 mbar the transmission of the gas phase varies between $0.980($ at $\mathrm{h} v=580 \mathrm{eV})$ and $0.998(\mathrm{at} \mathrm{h} v=1300 \mathrm{eV})$. (The values were calculated using the web interface of the Center for X-ray Optics at Lawrence Berkeley National Laboratory, Berkeley, CA: http://www-

cxro.lbl.gov/optical_constants/gastrn2.html). The error in the calculation of the depth-dependent $\mathrm{Cu}: \mathrm{O}$ stoichiometry that is caused by attenuation effects in the gas phase is therefore smaller than $2 \%$, well within the error bars in Fig. 4 .
[35] Yeh, J.J.; Lindau, I. Atomic Data and Nuclear Data Tables 1985, 32, 1.

[36] Hävecker, M.; Knop-Gericke, A.; Schedel-Niedrig, T.; Schlögl, R. Angew. Chem. Int. Ed. 1998, 37, 1939.

[37] Abate, M.; Goedkoop, J.B.; de Groot, F.M.F.; Grioni, M.; Fuggle, J.C.; Hofmann, S.; Petersen, H.; Sacchi, M. Surf. Interface Anal. 1992, 18, 65.

[38] Siegbahn, H. J. Phys. Chem. 1985, 89, 897.

[39] Wagner, L.F.; Spicer, W.E. Surf. Sci. 1974, 46, 301.

[40] Benndorf, C.; Egert, B.; Keller, G.; Seidel, H.; Thieme, F. J. Phys. Chem. Solids 1979, 40, 877.

[41] Bluhm, H.; Hävecker, M.; Knop-Gericke, A.; Kleimenov, E.; Teschner, D.; Schlögl, R.; Bukhtiyarov, V.I. in preparation.

[42] Daley, S.; Utz, A.; Trautman, T.; Ceyer, S.T. J. Am. Chem. Soc. 1994, 116, 6001.

[43] Ledentu, V.; Dong, W.; Sautet, P. J. Am. Chem. Soc. 2000, 122, 1796.

[44] Günther, M.M.; Ressler, T.; Bems, B.; Büscher, C.; Genger, T.; Hinrichsen, O.; Muhler, M.; Schlögl, R. Catal. Lett. 2001, 71,37 .

[45] Mavrikakis, M.; Hammer, B.; Nørskov, J.K. Phys. Rev. Lett. 1998, 81, 2819.

[46] Ertl, G. Surf. Sci. 1967, 6, 208.

[47] Ertl, G. Surf. Sci. 1967, 7, 309.

[48] Andreasen, A.; Lynggaard, H.; Stegelmann, C.; Stoltze, P. Surf. Sci. 2003, 544, 5.

[49] Li, W.X.; Stampfl, C.; Scheffler, M. Phys. Rev. B 2003, 68, 165412.

[50] Schimizu, T.; Tsukada, M. Surf. Sci. Lett. 1993, 295, L1017.

[51] Li, W.X.; Stampfl, C.; Scheffler, M. Phys. Rev. B 2002, 65, 075407.

[52] Li, W.X.; Stampfl, C.; Scheffler, M. Phys. Rev. Lett. 2003, 90, 256102.

[53] Reuter, K.; Stampfl, C.; Ganduglia-Pirovano, M. V.; Scheffler, M. Chem. Phys. Lett. 2002, 352, 311.

[54] Stampfl, C.; M. Scheffler, M. Phys. Rev. B 1996, 54, 2868.

[55] Carlisle, C.I.; Fujimoto, T.; Sim, W.S.; King, D.A. Surf. Sci. 470, 15 (2000).

[56] Schedel-Niedrig, T.; Neisius, T.; Böttger, I.; Kitzelmann, E.; Weinberg, G.; Demuth, D.; Schlögl, R. Phys. Chem. Chem. Phys. 2000, 2, 2407.

[57] Meima, G.R.; Knijf, L.M.; van Dillen, A.J.; Geus, J.W.; Bongaarts, J.E.; van Buren, F.R.; Delcour, K. Catal. Today 1987, 1,117 .

[58] Böttger, I.; Schedel-Niedrig, T.; Timpe, O.; Gottschall, R.; Hävecker, M.; Ressler, T.; Schlögl, R. Chem. Eur. J. 2000, 6, 1870 . 